\title{
Factors Associated with Breast Cancer Screening among Korean American Women in California: Results from the California Health Interview Survey 2015-2016
}

\author{
Shin-Young Lee ${ }^{1 *}$, Eunice Lee ${ }^{2}$, Bulaporn Natipagon-Shah ${ }^{3}$, Joy Toyama ${ }^{2}$
}

\begin{abstract}
Background: Few studies have examined preventive lifestyle behaviors and breast cancer (BC) screening behaviors simultaneously to determine whether $\mathrm{BC}$ screening behaviors are associated with preventive lifestyle behaviors. The purposes of this study are to (a) describe $\mathrm{BC}$ screening utilization and preventive lifestyle behaviors and (b) examine factors associated with BC utilization among Korean American (KA) women. Methods: Data from the 2015-2016 California Health Interview Survey were analyzed. Survey-weighted adjusted logistic regressions were used to determine whether preventive lifestyle behaviors and characteristics of KA women 50 years of age and older at the time of the survey were associated with obtaining mammograms. Results: Most participants were born outside of the US and had lived in the US for 15 years or more at the time of the survey. This study found that KA women who were 50-64 years old had 38 times greater odds of having ever had a mammogram and a 13 times greater odds of having a recent mammogram than those 65 and older. KA women who walked at least 10 minutes per week for transportation and leisure purposed were 61 times more likely to have ever had a mammogram than those who did not walk. Conclusion: This study provides important perspectives on associations of $\mathrm{BC}$ screening behaviors and preventive life-style behaviors, especially walking. Future research should be conducted to better understand the association between $\mathrm{BC}$ screening and preventive life-style behaviors and to develop feasible interventions to improve $\mathrm{BC}$ screening behaviors among KA women, particularly elderly and physically inactive ones.
\end{abstract}

Keywords: Breast cancer- screening- Korean American

Asian Pac J Cancer Prev, 19 (11), 3271-3277

\section{Introduction}

According to Surveillance, Epidemiology and End Results (SEER) data, breast cancer (BC) among Korean American (KA) women increased by 4.7 annual percentage points between 1990 and 2008 (Gomez et al., 2013). While invasive breast cancer rates for African American and Hispanic groups remained about the same, the rate among KA women almost doubled, from 26.1/100,000 in 1988 to 44.5/100,000 in 1997 (Deapen et al., 2002). A little less than two thirds of KAs are foreign-born (62\%), and 48\% immigrated within the past two decades (Pew Research Center, 2017). The increase in $\mathrm{BC}$ incidence rates among $\mathrm{KA}$ women might be attributed to their adoption of Westernized habits after immigration to the US. However, their BC screening rates have been suboptimal, possibly because of a lack of preventive health orientation (perceived importance of avoiding risk factors and detecting health problems early). Preventive health orientation among KA women has been reflected in an awareness of the importance of the early detection of cancer, the maintenance of healthy food consumption and regular exercise, and the need for regular checkups even when no symptoms are present (Lee, 2015). Indeed, KA women's most cited reason for not obtaining BC screening is a lack of symptoms because many KA women tend to believe that cancer screening tests are needed only after symptoms of cancer occur; such a belief reflects a lack of preventive health orientation (Lee, 2015). To better understand the reason for increasing $\mathrm{BC}$ incidence rates among KA women, it is essential to understand behavioral risk factors for $\mathrm{BC}$ as well as screening habits that could put KA women at risk. Such information could be used to develop interventions to change their behaviors and lower BC incidence rates. However, few researchers have examined risk factors for breast cancer or screening habits in this population.

KAs tend to not adhere to $\mathrm{BC}$ screening guidelines,

${ }^{1}$ Department of Nursing at Chosun University 309 Pilmun-daero, Dong-gu, Gwangju, Republic of Korea, ${ }^{2}$ School of Nursing, University of California, Los Angeles, California, ${ }^{3}$ School of Nursing, California State University, San Marcos, USA. *For Correspondence: shinyoung0114@gmail.com 
which could contribute to the increase in invasive $\mathrm{BC}$ in the population. Although the American Cancer Society (ACS) recommends that women aged 45 to 54 years receive a mammogram every year and women 55 years and older get a mammogram every other year (Oeffinger et al., 2015), less than $40 \%$ of KA women reported having a mammogram in the previous year (Choi, 2010; Lee, 2006; Wu, 2007) and less than $60 \%$ of KA women had had a mammogram in the previous two years (Jun and Nan, 2017; Juon, 2004; Lee, 2006; Lee et al., 2010; Pourat et al., 2010; Wismer et al., 1998). These rates are far below overall BC screening rates from $2013(72.6 \%)$ and the Healthy People 2020 target rate of $81.1 \%$ (National Cancer Institute, 2015).

The identified positive predictors for $\mathrm{BC}$ are being overweight or obese after menopause, drinking alcohol, and not being physically active (American Cancer Society, 2017). In the 2003 California Health Interview Survey, $38 \%$ of KAs were overweight and $8 \%$ were obese-rates higher than those of other ethnic groups and whites (Cho and Juon, 2006). In the study, respondents who were men, married, below the $100 \%$ federal poverty level, and had lived in the US for 15 years or more had higher BMIs. Another study of Asians in California showed that 33.8\% of men and $17.3 \%$ women had a BMI of 25 or higher (McCracken et al., 2007).

Among KAs in California, more than three quarters were physically inactive, with $78.6 \%$ of men and $75.2 \%$ of women walking less than 30 minutes at a time three or more days per week for transportation or fun, according to the 2003 California Health Interview Survey (McCracken et al., 2007). Among adults 45 to 75 years old in New York City, fewer than half $(141$ out of 292 participants $=48.3 \%$ ) had more than sufficient physical activity $(\geq 150 \mathrm{~min}$ per week) (Han et al., 2016). Sufficient physical activity was associated with being male, older, having a lower BMI, and eating vegetables daily.

Preventive health orientation influences BC and cervical cancer screening behaviors in KA women (Lee, 2015). People who have a prevention orientation are more likely to receive other types of screening, such as Pap smears or colorectal cancer screenings or flu shots. Smoking could also influence a preventive orientation, as smoking causes various types of cancer. A little more than a third of Korean men in California were current smokers $(36.2 \%)$, whereas $34.6 \%$ of them had never smoked (McCracken et al., 2007). Most KA women in the study had never smoked (83.2\%) (McCracken et al., 2007). However, to date, little research has been conducted to investigate whether KA women's smoking behaviors, one of the lifestyle behaviors, are associated with their $\mathrm{BC}$ screening behaviors. Therefore, the purposes of this study were to (a) describe BC screening utilization and other preventive lifestyle behaviors $t$ and (b) examine factors associated with $\mathrm{BC}$ utilization among KA women.

\section{Materials and Methods}

We used the 2015-2016 California Health Interview Survey (CHIS) data collected between May 2015 and
February 2016 for 2015 and between January and December 2016 for 2016. The CHIS was a populationbased telephone survey of noninstitutionalized residents living in California using a multistage stratified sample design to investigate socio-demographic information, health conditions, lifestyle behaviors, and health care utilization and access (California Health Interview Survey, 2017). In this study, we analyzed 191 KA women aged 50 or older by combining 2015 CHIS data $(\mathrm{N}=46)$ and 2016 CHIS data $(\mathrm{N}=145)$. The weighted percent of the total 15,774 women aged 50 or older, combining 2015 and 2016 CHIS data, is presented as a comparison to the corresponding percent of KA women. We used the final weight variable along with replicate weights to obtain correct variance estimates and point estimates. Including the weights so that the sample of Korean women are representative of the California population does drastically impact the OR, but this is with the goal of reducing the overall bias.

Data were analyzed using SAS 9.4. Sample characteristics and mammogram rates were described with percentages and $95 \%$ confidence intervals. To clarify associations between independent variables (demographic information [age, place of birth, years in US, marital status, education, employment, English proficiency, annual household income], health conditions [general health condition, BMI], health care utilization and access [doctor visits in past 12 months, insurance status, consistent source of health care], lifestyle behaviors [flu shot in past 12 months, regular walk and leisure at least 10 minutes for transport and for leisure in the past 7 days, drinking soda in the last month and fast food in the past week, current smoking]), and outcome variables (mammogram in lifetime, mammogram in the past 2 years), logistic regressions were conducted between these variables and the outcome variables. Bivariate variable with probabilities less than 0.2 were entered into a binary logistic regression, with a final parsimonious model obtained using backward selection.

Although drinking alcohol is one of predictors for having $\mathrm{BC}$, relationships with other types of cancer screening behaviors and alcohol use with mammogram screening are obscured because the CHIS 2015-2016 data do not include any relevant variables. Due to the nature of survey data, the weighted population percentages are provided in lieu of the large values calculated for the weighted population frequencies.

\section{Results}

Sample characteristics and preventive lifestyle behaviors

Table 1 presents demographic information, health conditions, health care utilization and access, and lifestyle behaviors in the present study. Most KA women were born outside of the US (96.75\%) and lived in the US for 15 years or more $(95.37 \%)$. Among all women in the 2015-2016 CHIS data, only $32.05 \%$ of women were born outside of the US. More than half of the KA women were currently married $(70.19 \%)$, had a college degree or more $(58.11 \%)$, and were not employed (51.06\%). Although more than half of the participants had at least a college degree, only 
Table 1. Univariate Results for Sample Characteristics $($ Korean $=191 ;$ Overall $=15,774)$

\begin{tabular}{|c|c|c|}
\hline Variable & $\begin{array}{l}\text { Korean Percent } \\
(95 \% \mathrm{CI})\end{array}$ & $\begin{array}{l}\text { Overall Percent } \\
(95 \% \text { CI })^{*}\end{array}$ \\
\hline \multicolumn{3}{|c|}{ Demographic Information } \\
\hline \multicolumn{3}{|l|}{ Age } \\
\hline $50-64$ & $61.96(39.71-84.22)$ & $56.71(56.22-57.21)$ \\
\hline 65 or older & $38.04(15.78-60.29)$ & $43.29(42.79-43.78)$ \\
\hline \multicolumn{3}{|l|}{ Born in US } \\
\hline In US & $3.25(0-9.71)$ & $67.95(65.71-70.18)$ \\
\hline Outside US & $96.75(90.29-100)$ & $32.05(29.82-34.29)$ \\
\hline \multicolumn{3}{|l|}{ Years in US } \\
\hline Less than 15 years & $4.63(0-11.98)$ & $3.19(2.33-4.06)$ \\
\hline 15 years or more & $95.37(88.02-100)$ & $96.81(95.94-97.67)$ \\
\hline \multicolumn{3}{|l|}{ Marital Status } \\
\hline $\begin{array}{l}\text { Not married } \\
\text { (Separated/Divorced/ } \\
\text { Widowed) }\end{array}$ & $29.81(11.3-48.32)$ & $42.49(40.31-44.66)$ \\
\hline $\begin{array}{l}\text { Currently married/ } \\
\text { Living with partner }\end{array}$ & $70.19(51.68-88.7)$ & $57.51(55.34-59.69)$ \\
\hline \multicolumn{3}{|l|}{ Education } \\
\hline High school or less & $41.89(17.94-65.83)$ & $39.97(38.24-41.7)$ \\
\hline College or more & $58.11(34.17-82.06)$ & $60.03(58.3-61.76)$ \\
\hline \multicolumn{3}{|l|}{ Employment } \\
\hline Not employed & $51.06(22.93-79.2)$ & $58.33(56.24-60.42)$ \\
\hline Employed & $48.94(20.8-77.07)$ & $41.67(39.58-43.76)$ \\
\hline \multicolumn{3}{|l|}{ English proficiency } \\
\hline $\begin{array}{l}\text { Not well/none } \\
\text { at all }\end{array}$ & $41.89(16.05-67.73)$ & $16.27(14.5-18.03)$ \\
\hline Very well/well & $35.07(6.19-63.96)$ & $18.83(16.84-20.82)$ \\
\hline Missing & $23.04(0-48.96)$ & $64.9(62.79-67.02)$ \\
\hline \multicolumn{3}{|c|}{ Annual household income } \\
\hline Less than $\$ 30,000$ & $28.72(8.36-49.07)$ & $33.22(31.33-35.12)$ \\
\hline $\begin{array}{l}\text { Equal to or more } \\
\text { than } \$ 30,000\end{array}$ & $71.28(50.93-91.64)$ & $66.78(64.88-68.67)$ \\
\hline \multicolumn{3}{|l|}{ Health Conditions } \\
\hline \multicolumn{3}{|c|}{ General health condition } \\
\hline Fair/poor & $43.78(16.93-70.63)$ & $29.41(27.39-31.42)$ \\
\hline $\begin{array}{l}\text { Excellent/very } \\
\text { good/good }\end{array}$ & $56.22(29.37-83.07)$ & $70.59(68.58-72.61)$ \\
\hline \multicolumn{3}{|l|}{ BMI } \\
\hline Less than 23 & $55.27(32.93-77.62)$ & $23.27(21.58-24.97)$ \\
\hline 23 or more & $44.73(22.38-67.07)$ & $76.73(75.03-78.42)$ \\
\hline \multicolumn{3}{|c|}{ Health Care Utilization and Access } \\
\hline \multicolumn{3}{|c|}{ Doctor visits in past 12 months } \\
\hline No & $18.97(0-41.46)$ & $10.92(9.41-12.43)$ \\
\hline Yes & $81.03(58.54-100)$ & $89.08(87.57-90.59)$ \\
\hline \multicolumn{3}{|l|}{ Currently insured } \\
\hline No & $7.3(0-20.97)$ & $4.83(3.57-6.1)$ \\
\hline Yes & $92.7(79.03-100)$ & $95.17(93.9-96.43)$ \\
\hline \multicolumn{3}{|c|}{ Usual source of health care } \\
\hline No & $17.02(0-40.92)$ & $7.11(5.81-8.42)$ \\
\hline Yes & $82.98(59.08-100)$ & $92.89(91.58-94.19)$ \\
\hline
\end{tabular}

Table 1. Continued

\begin{tabular}{lcc}
\hline Variable & $\begin{array}{c}\text { Korean Percent } \\
(95 \% \mathrm{CI})\end{array}$ & $\begin{array}{c}\text { Overall Percent } \\
(95 \% \mathrm{CI})^{*}\end{array}$ \\
\hline Lifestyle behaviors & & \\
Flu shot in past 12 months & \\
No & $42.6(17.49-67.71)$ & $42.35(40.21-44.5)$ \\
Yes & $57.4(32.29-82.51)$ & $57.65(55.5-59.79)$
\end{tabular}

Regular walk and leisure at least 10 minutes past week

\begin{tabular}{|c|c|c|}
\hline $\begin{array}{l}\text { Never/walk for } \\
\text { transport or leisure }\end{array}$ & $62.59(35.52-89.67)$ & $63.6(61.83-65.36)$ \\
\hline $\begin{array}{l}\text { Walk for both } \\
\text { transport and leisure }\end{array}$ & $37.41(10.33-64.48)$ & $36.4(34.64-38.17)$ \\
\hline \multicolumn{3}{|c|}{ Ingesting soda in last month and fast food in past week } \\
\hline $\begin{array}{l}\text { Never/either soda } \\
\text { or fast food }\end{array}$ & $77.51(55.32-99.7)$ & $77.94(75.75-80.13)$ \\
\hline $\begin{array}{l}\text { Both soda and fast } \\
\text { food }\end{array}$ & $22.49(0.3-44.68)$ & $22.06(19.87-24.25)$ \\
\hline \multicolumn{3}{|l|}{ Current smoking } \\
\hline No & $97.61(92.88-100)$ & $91.2(90.12-92.27)$ \\
\hline Yes & $2.39(0-7.12)$ & $8.8(7.73-9.88)$ \\
\hline
\end{tabular}

* Regular walk and leisure for at least 10 minutes was coded if the participant reported walking for at least 10 minutes for transport and/ or leisure during the past 7 days; * Ingesting soda in the last month and fast food in the past week was coded if the participant reported drinking soda in the last month and eating fast food in the past week; *Overall percent is weighted percent of all women over 50 years old in 2015-2016 CHIS data.

$35.7 \%$ of participants rated their English proficiency as very well or well. The majority of participants $(71.28 \%)$ had an annual income equal to or more than $\$ 30,000$.

More than half of the participants rated their health as good, very good, or excellent (56.22\%) and had a BMI less than 23 (55.27\%), while only $23.27 \%$ of women in the CHIS data had a BMI less than 23. Most KA women had visited a doctor in the previous 12 months $(81.03 \%)$, were currently insured $(92.7 \%)$, and had a consistent source of health care $(82.98 \%)$ ). A little more than half of KAs in the study had received a flu shot in the previous 12 months (57.4\%). More than half of the participants had not taken regular walks for at least 10 minutes in the past 7 days (62.59\%). However, the majority of them had not had soda in the previous month or eaten fast food in the past week $(77.51 \%)$. Only $2.39 \%$ of the KA women in the sample were current smokers. Lifestyle behaviors between KA women and all women in the CHIS were fairly similar (Table 1).

Table 2. Mammogram Rates $($ Korean $=191$; Overall $=$ 15,774)

\begin{tabular}{|c|c|c|}
\hline Mammogram & $\begin{array}{l}\text { Korean Percent } \\
(95 \% \mathrm{CI})\end{array}$ & $\begin{array}{l}\text { Overall Percent } \\
(95 \% \mathrm{CI})\end{array}$ \\
\hline \multicolumn{3}{|c|}{ Lifetime mammogram } \\
\hline Never had one & $5.32(0-12.33)$ & $3.03(2.19-3.87)$ \\
\hline Ever had one & $94.68(87.67-100)$ & $96.97(96.13-97.81)$ \\
\hline \multicolumn{3}{|c|}{ Mammogram in past 2 years } \\
\hline No & $31.27(11.04-51.5)$ & $20.32(18.2-22.43)$ \\
\hline Yes & $68.73(48.5-88.96)$ & $79.68(77.57-81.8)$ \\
\hline
\end{tabular}

Asian Pacific Journal of Cancer Prevention, Vol $19 \mathbf{3 2 7 3}$ 
Table 3. Bivariate Association among Variables in KA women

\begin{tabular}{|c|c|c|}
\hline Variables & $\begin{array}{l}\text { Mammogram } \\
\text { in lifetimea }\end{array}$ & $\begin{array}{c}\text { Mammogram } \\
\text { in past } 2 \\
\text { yearsa }\end{array}$ \\
\hline \multicolumn{3}{|l|}{ Demographic Information } \\
\hline Age & $0.0035^{* *}$ & $0.011 *$ \\
\hline Born in US & 0.97 & 0.42 \\
\hline Years in US & 0.47 & 0.93 \\
\hline Marital status & 0.13 & 0.17 \\
\hline Education & 0.91 & 0.8 \\
\hline Employment & 0.18 & 0.24 \\
\hline English proficiency & 0.73 & 0.58 \\
\hline Annual household income & 0.2 & 0.52 \\
\hline \multicolumn{3}{|l|}{ Health Conditions } \\
\hline General health condition & 0.068 & 0.27 \\
\hline BMI & 0.67 & 0.95 \\
\hline \multicolumn{3}{|l|}{ Health Care Utilization and Access } \\
\hline Doctor visits in past 12 months & 0.63 & 0.39 \\
\hline Currently insured & 0.43 & 0.99 \\
\hline Usual source of health care & 0.36 & 0.77 \\
\hline \multicolumn{3}{|l|}{ Lifestyle behaviors } \\
\hline Flu shot in past 12 months & 0.63 & 0.28 \\
\hline $\begin{array}{l}\text { Walk and leisure at least } 10 \\
\text { minutes }\end{array}$ & $0.015^{*}$ & 0.34 \\
\hline Ingesting soda and fast food & 0.9 & 0.27 \\
\hline Current smoking & 0.8 & 0.4 \\
\hline
\end{tabular}

\section{Mammogram utilization}

A total of $94.68 \%$ of KA women reported ever having had a mammogram in their lifetime, and $68.73 \%$ had had a mammogram in the past two years (Table 2). In contrast, among the entire population of women in the 2015-2016 CHIS database, $96.97 \%$ had ever had a mammogram and $79.68 \%$ had had a mammogram in the past two years.

Factors associated with mammogram utilization in $K A$ women

As shown in Table 3, bivariate analyses indicated that demographic information (age) and lifestyle behaviors (walk for transport or leisure at least 10 minutes per week) were significantly associated with mammogram uptake over a lifetime. However, only age was significantly associated with having had a mammogram in the past two years. These significant variables were used in a logistic regression analysis. The final logistic regression model showed that age and walking for transport or leisure at least 10 minutes in the last 7 days are variables for having had mammogram over a lifetime (Table 4). After controlling for walking, the model indicated that KA women who are 50-64 years old have 38 times greater odds of having ever had a mammogram than those 65 years or older $(\mathrm{OR}=37.98,95 \% \mathrm{CI}=2.76-523)$; after controlling for age, the odds of KA women who walk for transport and leisure at least 10 minutes per week are 61 times higher for having ever had a mammogram than those who do not walk $(\mathrm{OR}=61.39,95 \% \mathrm{CI}=$ 2-1882.6). Only one significant variable of having had a mammogram in the past two years was age (Table 4 ). The odds of KA women 50-64 years old having had a recent mammogram is 13 times higher than those 65 years or older $(\mathrm{OR}=13.27,95 \% \mathrm{CI}=1.84-95.6)$.

\section{Discussion}

This study aimed to describe BC screening utilization and preventive lifestyle behaviors as well as examine factors associated with BC utilization among KA women. This study examined demographic information, health conditions, health care utilization and access, and preventive lifestyle behaviors in the first attempt to investigate the relationships between the preventive lifestyle factors and $\mathrm{BC}$ screening utilization among KA women. Few studies have examined health-related preventive lifestyle behaviors and screening behaviors simultaneously to investigate whether BC screening behaviors are associated with preventive lifestyle behaviors. Understanding how these two types of cancer prevention behaviors are associated could help develop effective strategies to improve $\mathrm{BC}$ prevention efforts among KA women.

According to CHIS 2015-2016 data, most variables of demographics, health conditions, health care utilizations and access, and lifestyle behaviors among KA women were similar to those among women in California in general. However, some differences emerged between the two groups: More KA women were born outside the US than women in general $(96.75 \%$ vs. $32.05 \%$, respectively); KA women's English proficiency was not as high as that of women overall (41.89\% vs. $16.27 \%)$; KA women's perceived general health conditions were poorer than women in general (43.78\% vs. $29.41 \%$ ); and KA

Table 4. Logistic Regression for Mammograms in KA Women

\begin{tabular}{|c|c|c|c|c|}
\hline & \multicolumn{2}{|c|}{ Up-to-date Mammogram in the past 2 years } & \multicolumn{2}{|c|}{ Lifetime Mammogram } \\
\hline & Odds Ratio & $95 \% \mathrm{CI}$ & Odds Ratio & $95 \% \mathrm{CI}$ \\
\hline \multicolumn{5}{|l|}{ Age } \\
\hline $50-64$ & $13.27 *$ & $(1.84,95.6)$ & $37.98 * *$ & $(2.76,522.68)$ \\
\hline 65 or older & -- & -- & -- & -- \\
\hline \multicolumn{5}{|c|}{ Walk for transport and leisure (at least 10 minutes) } \\
\hline Walk for bo & ure & & $61.39^{*}$ & $(2.00,1882.6)$ \\
\hline Never/walk & ure & & -- & -- \\
\hline
\end{tabular}


women's BMIs were lower than BMIs in women overall (55.27\% vs. $23.27 \%$ ). KA women were immigrants and possibly less acculturated because of language barriers and poorer health.

In this study, BC screening rates in the past two years $(68.73 \%)$ were higher than published reports of less than $60 \%$ of women receiving mammograms in the previous two years (Jun and Nan, 2017; Juon, 2004; Lee, 2006; Lee et al., 2010; Pourat et al., 2010; Wismer et al., 1998). This study found that $\mathrm{BC}$ screening rates among KA women are increasing, but still not meeting the Healthy People 2020 goal of $81.1 \%$; moreover, they are still lower than $72.6 \%$ of women in the US (National Cancer Institute, 2015). Meanwhile, the BC screening rate of women in California (79.68\% according to the 2015-2016 CHIS data) is close to the Healthy People 2020 goal. BC screening results in a significant reduction in BC mortality rates. In an incidence-based mortality study, the pooled mortality reduction was $38 \%$ (RR, $0.62 ; 95 \% \mathrm{CI}$ 0.56-0.69) among European women having ever had a mammogram screening (Broeder et al., 2012).

Weighted OR estimates and confidence intervals result in relatively large ORs. After controlling for walking for transport or leisure, this study found that KA women aged 50-64 years old had 38 times greater odds of a lifetime mammogram than those 65 or older. Also, after controlling for age, KA women walking for both transport and leisure had 62 times greater odds of a lifetime mammogram than those who did not walk.

Among variables of demographic information, health conditions, health care utilization and access, and lifestyle behaviors, age was significantly associated with mammogram uptake over a lifetime and in the past 2 years in this study. KA women aged 50-64 years old had 38 times greater odds of having ever had a mammogram or 13 times greater odds of having had a recent mammogram than those aged 65 or older. However, some studies reported that age was not associated with BC screening (Lee et al., 2015; Ryu et al., 2013), whereas others reported significant associations with age and BC screening (Juon et al., 2004; Lee et al., 2016; Lee et al., 2006). In our study, lower ORs of both lifetime and up-to-date mammograms were found in KA women aged 65 or older compared to women aged 50-64. Similarly, a previous study reported that the lowest rates of women ever having had a BC screening were among KA women 65 years of age or older, indicating that older KA women may face language barriers or less acculturation issues (Lee et al., 2006). Another study indicated that older KA women had lower cervical cancer screening rates because of cultural barriers (e.g., lack of proficiency in English, embarrassment, no symptoms) (Lee et al., 2012). Despite the variability of age and $\mathrm{BC}$ screening findings in previous studies, women aged 65 or older are still at risk of developing $\mathrm{BC}$ because $\mathrm{BC}$ incidence and mortality rates increase with age (Natinal Cancer Institute, 2012). BC incidence rates begin to increase after age 40 and are highest in women over age 70 (Natinal Cancer Institute, 2012). Therefore, encouraging cancer screening in high-risk groups is important, and BC screening should be more encouraged among elderly KA women.
Among health-related preventive lifestyle behaviors, only physical activity (walk for transport or leisure at least 10 minutes per week) was significantly associated with a mammogram uptake in the lifetime. KA women who walk for transport and leisure at least 10 minutes per week are 61 times more likely to have ever had a mammogram than those who do not walk. Although few studies have addressed lifestyle and BC behaviors simultaneously among KA women, the findings of this study are consistent with studies of Korean women in the Republic of Korea (Jeong et al., 2004; Kim et al., 2014); however, they are inconsistent with Americans in the US (Bostean et al., 2013). A total of 342 Korean women aged 40 to 69 in the Republic of Korea were surveyed, and regular exercise was statistically significantly related to BC screening $(\mathrm{OR}=2.76$; 95\% CI $=1.49-4.76)$ (Jeong et al., 2004). In addition, 425 Korean elderly people aged 65 or older in the Republic of Korea were investigated, and exercise was a predictor of cancer screening behaviors (Kim et al., 2014). Koreans who exercised three to four times per week were more likely to undergo cancer screening (OR $=3.24 ; 95 \% \mathrm{CI}=1.19-8.83$ ) (Kim et al., 2014). On the other hand, another CHIS study (Bostean et al., 2013) reported that lifestyle behaviors including smoking, physical activity, diet, and alcohol consumption were not significantly associated with BC screening among Asians, but physical activity of more 150 minutes per week was associated with up-to-date colorectal cancer screening among Asian males. Although measurements of physical activity, time, and geographic variations of studies made it difficult to compare the findings of these studies, it is certain that increasing physical activity as well as improving other lifestyle behaviors reduces the risk of $\mathrm{BC}$ and may also increase $\mathrm{BC}$ screening and possibly other cancer screenings.

Cancer, including $\mathrm{BC}$, is strongly associated with modifiable lifestyle factors, such as obesity, physical inactivity, heavy alcohol intake, and dietary habits (Friedenreich, 2001). Approximately 30\%-40\% of cancers can be prevented by modifying lifestyle factors such as physical activity and diet (American Institute for Cancer Research, 2007). For example, Moore and his colleagues examined hazard rations for associations of leisure-time physical activity with the incidence of 26 types of cancer using pooled data from 12 prospective American and European cohorts with self-reported physical activity among a total of 1.44 million participants (mean age: 59 years, range 19-98 years) (Moore et al., 2016). In that study, high versus low levels of leisure-time physical activity were associated with lower risks of 13 cancers, including $\mathrm{BC}(\mathrm{HR}=0.90 ; \mathrm{CI}=0.87-0.93$ ) (Moore et al., 2016).

Healthier lifestyle behaviors are also generally associated with a higher likelihood of cancer screening (Bostean et al., 2013). For example, physical activity may be associated with compliance with cancer screening recommendations (Courneya and Friedenreich, 2007). Preventive health orientation may aid in the interpretation of these associations. KAs who have a preventive health orientation are more likely to engage in physical activity and undergo BC screening (Lee, 2015). KAs are 
more likely to be more familiar with healthy lifestyle prevention, such as healthy diet or regular exercise, than cancer screening because of traditional values and beliefs, including traditional Korean medicine emphasizing herbal medicine, dietary therapy, exercise, and massage (Lin et al., 2017; National Center for Complementary and Integrative Health, 2017). To improve lifestyle and $\mathrm{BC}$ screening behaviors among KA women, improving preventive health orientation and behaviors may be an effective strategy for future intervention.

For preventive lifestyle and $\mathrm{BC}$ screening behaviors among KA women, we may need to consider interpersonal and community factors in addition to individual factors to better identify correlates of prevention behaviors (Glanz et al., 2015). Community factors such as policies to promote cancer prevention or having a public place to walk might be more effective in shaping preventive lifestyle behaviors than individual health education alone (Bostean et al., 2013).

This study was limited to causal relationships among variables and the generalizability of a national population due to its cross-sectional and self-reported study design and the probability sample in California. Future research may need to address time and geographic variabilities in these findings. Furthermore, this study examined demographic variables, lifestyle, and BC screening behaviors, but did not examine psychosocial factors. Investigating psychosocial factors in addition to the variables measured in this study will provide a more comprehensive and accurate understanding of $\mathrm{BC}$ preventive behaviors. For example, a cross-sectional survey of $202 \mathrm{KA}$ immigrant women revealed that, after controlling for socio-demographic characteristics, immigration, and health accessibility factors, the odds of having a mammogram were increasingly greater for women who were younger $(\mathrm{OR}=0.90, \mathrm{p}=0.002)$ (Lee et al., 2015) as a result of hierarchical logistic regression. However, when the health belief model constructs (susceptibility, benefits, barriers, motivation, life in danger, cancer anxiety, confidence) were entered, age was not associated with getting a mammogram, and barriers and confidence became significant predictors of it (Lee et al., 2015).

Despite these limitations, this study is a populationbased sample examining preventive lifestyle variables and $\mathrm{BC}$ screening among KA women. It provides important perspectives on associations of $\mathrm{BC}$ screening behaviors and preventive life-style behaviors. Given the fact that $\mathrm{BC}$ is preventable, this study's findings contribute to the understanding of $\mathrm{BC}$ preventive behaviors among $\mathrm{KA}$ women. Interventions should aim at increasing awareness of the importance of $\mathrm{BC}$ prevention using strategies that consider individual, interpersonal, and community factors to change both preventive life lifestyle and $\mathrm{BC}$ screening behaviors. In addition, this study indicated that interventions should target women who are older and less physically active. Future research should be conducted to better understand preventive life-style behavioral risk factors for $\mathrm{BC}$ and to develop feasible interventions to improve lifestyle and screening behaviors among KA women.

\section{References}

American Cancer Society (2017). Lifestyle-related Breast Cancer Risk Factors. Retrieved from https://www.cancer.org/cancer/ breast-cancer/risk-and-prevention/lifestyle-related-breastcancer-risk-factors.html.

American Institute for Cancer Research (2007). Food, Nutrition and the Prevention of Cancer: a global perspective. Washington, DC: American Institute for Cancer Research.

Bostean G, Crespi CM, McCarthy WJ (2013). Associations among family history of cancer, cancer screening and lifestyle behaviors: A population-based study. Cancer Causes Control, 24, 1491-503.

Broeder M, Moss S, Nystrom L, et al (2012). The impact of mammographic screening on breast cancer mortality in Europe: a review of observational studies. J Med Screen, 19, 14-25.

California Health Interview Survey (2017). CHIS 2016 Adult Survey. Los Angeles, CA: UCLA Center for Health Policy Research.

Cho J, Juon HS (2006). Assessing overweight and obesity risk among Korean Americans in California using World Health Organization body mass index criteria for Asians. Prev Chronic Dis, 3, A79.

Choi KS (2010). Comparison of breast cancer screening rates between Korean women in America versus Korea. $J$ Womens Health, 19, 1089-96.

Courneya KS, Friedenreich CM (2007). Physical activity and cancer control. Semin Oncol Nurs, 23, 242-52.

Deapen D, Liu L, Perkins C, et al (2002). Rapidly rising breast cancer incidence rates among Asian-American women. Int $J$ Cancer, 99, 747-50.

Friedenreich CM (2001). Physical activity and cancer prevention: from observational to intervention research. Cancer Epidemiol Biomarkers Prev, 10, 287-301.

Glanz K, Rimer B, Viswanath K (2015). Health behavior and health education: theory, research, and practice. San Francisco, CA: John Wiley and Sons, Inc.

Gomez SL, Noone A-M, Lichtensztajn DY, et al (2013). Cancer incidence trends among Asian American populations in the United States, 1990-2008. J Natl Cancer Inst, 105, 1096-110.

Han BH, Sadarangani T, Wyatt LC, et al (2016). Correlates of physical activity among middle-aged and older Korean Americans at risk for diabetes. J Nurs Scholarsh, 48, 48-57.

Jeong I, Ju H, Bae E (2004). Related factors to screening or repeat screening for cervical and breast cancer among women. Korean J Women Health Nurs, 10, 150-61.

Jun J, Nan X (2017). Determinants of cancer screening disparities among Asian Americans: A systematic review of public health surveys. $J$ Cancer Educ. In press.

Juon H-S, Kim M, Shankar S, Han W (2004). Predictors of adherence to screening mammography among Korean American women. Prev Med, 39, 474-81.

Kim H, Yim H, Kim N (2014). Factors affecting cancer screening intention and behavior of the Korean elderly. Asian Pac J Cancer Prev, 15, 8461-67.

Lee E, Nandy K, Szalacha L, et al (2016). Korean American women and mammogram uptake. J Immigr Minor Health, 18, 179-86.

Lee EE, Fogg LF, Sadler GR (2006). Factors of breast cancer screening among Korean immigrants in the United States. J Immigr Minor Health, 8, 223-33.

Lee EE, Eun Y, Lee S-Y, Nandy K (2012). Age-related differences in health beliefs regarding cervical cancer screening among Korean American women. J Transcult Nurs, 23, 237-45.

Lee HY, Ju E, Vang PD, Lundquist M (2010). Breast and cervical 
cancer screening among Asian American women and latinas: does race/ethnicity matter?. J Womens Health, 19, 1877-84.

Lee HY, Stange MJ, Ahluwalia JS (2015). Breast cancer screening behaviors among Korean American immigrant women: Findings from the Health Belief Model. J Transcult Nurs, 26, 450-7.

Lee S-Y (2015). Cultural factors associated with breast and cervical cancer screening in Korean American women in the US: An integrative literature review. Asian Nurs Res, 9, 81-90.

Lin SA, Chu P, Chen L, et al (2017). The prevalence rate of deviations in body constitutions and related factors in follow-up stage breast cancer patients-A nationwide study. Complement Ther Med, 32, 49-55.

McCracken M, Olsen M, Chen MS, et al (2007). Cancer incidence, mortality, and associated risk factors among Asian Americans of Chinese, Filipino, Vietnamese, Korean, and Japanese ethnicities. CA Cancer J Clin, 57, 190-205.

Moore SC, Lee I-M, Weiderpass E, et al (2016). Leisure-time physicial activity and risk of 26 types of cancer in 1.44 million adults. JAMA Intern Med, 176, 816-25.

Natinal Cancer Institute (2012). Breast cancer risk in American Women. Retrieved from https://www.cancer.gov/types/ breast/risk-fact-sheet.

National Cancer Institute (2015). Screening rates for several cancers miss their targets. Retrieved from https://www. cancer.gov/news-events/cancer-currents-blog/2015/ screening-targets.

National Center for Complementary and Integrative Health (2017). Traditional Chinese medicine. Retrieved from https:// nccih.nih.gov/health/whatiscam/chinesemed.htm.

Oeffinger KC, Fontham ET, Etzioni R, et al (2015). Breast cancer screening for women at average risk: 2015 guideline update from the American Cancer Society. JAMA, 314, 1599-614.

Pew Research Center (2017). Koreans in the U.S. Fact Sheet. Retrieved from http://www.pewsocialtrends.org/fact-sheet/ asian-americans-koreans-in-the-u-s/.

Pourat N, Kagawa-Singer M, Breen N, Sripipatana A (2010). Access versus acculturation: Identifying modifiable factors to promote cancer screening among Asian American women. Med Care, 48, 1088-96.

Ryu SY, Crespi CM, Maxwell AE (2013). What factors explain disparities in mammography rates among Asian-American immigrant women? A population-based study in California. Womens Health Issues, 23, e403-10.

Wismer BA, Moskowitz JM, Chen AM, et al (1998). Mammography and clinical breast examination among Korean American women in two California counties. Prev Med, 27, 144-51.

Wu T-Y (2007). Mammography stage of adoption and decision balance among Asian Indian and Filipino American women. Cancer Nurs, 30, 390-8.

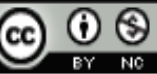

This work is licensed under a Creative Commons AttributionNon Commercial 4.0 International License. 